\title{
Is It Relevant to Screen Subclinical Cushing's Syndrome in Patients With Type 2 Diabetes Mellitus?
}

\author{
Manel Jemel Hadiji ${ }^{a}$, c, Imen Ksira ${ }^{a}$, Emna Haouat ${ }^{a}$, Henda Kammoun Jamoussi ${ }^{b}$, \\ Leila Ben Salem Hachmib
}

\begin{abstract}
Background: Subclinical Cushing's syndrome (SCS) is defined as autonomous cortisol secretion in patients devoid of specific clinical symptoms of hypercortisolism, as in the classic CS. However, sustained exposure to chronic slightly elevated cortisol concentrations may result in some classical metabolic complications of CS such as impaired glucose tolerance and diabetes. Currently, the frequency of SCS is widely variable. We have conducted a cross-sectional study to prospectively evaluate the prevalence of SCS among type 2 diabetic (T2D) patients with poor control, and to determine whether systematic screening for SCS in T2D patients is worthwhile.
\end{abstract}

Methods: It was a cross-sectional study including $221 \mathrm{~T} 2 \mathrm{D}$ patients referred to the National Institute of Nutrition of Tunis for poor glycemic control (HbA1c $\geq 8 \%$ ). The first screening step of SCS was the 1-mg overnight dexamethasone suppression test (ODST) using a revised criterion for cortisol suppression. In the second confirmatory step, patients with abnormal ODST underwent a 48-h, 2-mg low-dose dexamethasone suppression test (LDDST) to confirm the diagnosis. The cut-off for cortisol suppression was $50 \mathrm{nmol} / \mathrm{L}(1.8 \mu \mathrm{mol} / \mathrm{dL})$ in the two tests.

Results: Thirteen patients (5.9\%) failed to suppress cortisol levels less than the cut-off after ODST. SCS was confirmed by LDDST in one patient among them $(0.45 \%)$. The autonomous cortisol secretion was related to a pituitary adenoma. Our study revealed that the frequency of SCS of $0.45 \%$ did not allow performing an analytical study in order to identify predictive factors of SCS among T2D patients.

Conclusion: SCS is rare among T2D patients. Systematic screening of SCS in T2D patients with poor glycemic control is not worthwhile. The screening should be performed only in patients with a particular clinical and/or biological context.

Keywords: Type 2 diabetes; Cushing's syndrome; Dexamathasone suppression test; Obesity; Metabolic syndrome

Manuscript submitted October 2, 2017, accepted October 27, 2017

aDepartment B, National Institute of Nutrition, Tunis, Tunisia ${ }^{b}$ Department A, National Institute of Nutrition, Tunis, Tunisia

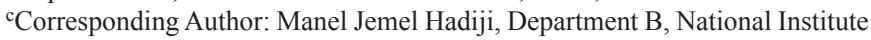
of Nutrition, Tunis, Tunisia. Email: maneljemel@gmail.com

doi: https://doi.org/10.14740/jem454w

\section{Introduction}

Cushing's syndrome (CS) includes clinical and biological features induced by the chronic exposure to glucocorticosteroid excess $[1,2]$ with an estimated incidence between 1.8 and 2.5 cases per million inhabitants per year [3-5].

A variable autonomous cortisol secretion without specific signs and symptoms of classical CS characterizes subclinical CS (SCS), another entity recently described. This form is much more frequent than CS with an estimated incidence of eight cases per 10 thousand inhabitants per year [6] and a frequency of $0.2-2 \%$ in the general population [7].

It was suggested that sustained exposure to chronic moderate hypersecretion of cortisol is sufficient to induce metabolic complications, especially insulin resistance and diabetes [8-13].

Moreover, several studies have reported a higher frequency of SCS in type 2 diabetics [14] which can be considered an exacerbating factor for diabetes and poor glycemic control [15].

In this study, we aimed to investigate the frequency of SCS in patients with poor glycemic control.

\section{Patients and Methods}

\section{Patients}

Our cross-sectional study enrolled 221 patients with type 2 diabetes studied as inpatients and outpatients referred to the National Institute of Nutrition and Food Technology from April 2014 to March 2015 for poor glycemic control. Institutional Ethnics Committee approved the study protocol and all patients have signed informed consent to participate in the study. The patients were clinically examined by a single endocrinologist.

Our inclusion criteria were patients greater than 40 years of age with an $\mathrm{HbA} 1 \mathrm{c} \geq 8 \%$. Discriminatory features included particular pattern of CS: easy bruising, facial plethora proximal muscles weakness, and/or striae especially if reddish purple and large more than $1 \mathrm{~cm}$ wide. Patients with history of adrenal mass or pituitary adenoma were excluded. Pregnant women, and women using oral contraceptive pills, patients on anti-epileptic drugs or anti-tubercular medication, and patients with renal failure (creatinine clearance $<60 \mathrm{~mL}$ / 
Table 1. Comparison of Characteristics of Patients According to ODST

\begin{tabular}{llll}
\hline & Cortisol $\geq \mathbf{5 0} \mathbf{~ n m o l} / \mathbf{L}$ & Cortisol $<\mathbf{5 0} \mathbf{~ m m o l} / \mathbf{L}$ & P \\
\hline Male (n) & 2 & 66 & 0.18 \\
Female (n) & 11 & 142 & 0.18 \\
Age (years) & $59 \pm 8$ & $58.6 \pm 8.8$ & 0.9 \\
BMI $\left(\mathrm{kg} / \mathrm{m}^{2}\right)$ & $33.65 \pm 6.5$ & $29.9 \pm 5.3$ & 0.016 \\
Waist circumference (cm) & $104.46 \pm 13.4$ & $101.5 \pm 11.74$ & 0.39 \\
Type 2 diabetes duration (years) & $9.38 \pm 4.2$ & $10.9 \pm 6.7$ & 0.41 \\
Triglycerides (mmol/L) & $1.73 \pm 0.62$ & $1.84 \pm 1.06$ & 0.71 \\
Total cholesterol (mmol/L) & $4.46 \pm 1.55$ & $4.98 \pm 1.18$ & 0.26 \\
LDL-cholesterol (mmol/L) & $1.08 \pm 0.51$ & $1.16 \pm 0.37$ & 0.42 \\
HDL-cholesterol (mmol/L) & $1.03 \pm 0.28$ & $1.14 \pm 0.28$ & 0.19 \\
HbA1c (\%) & $11.5 \pm 2.4$ & $10.8 \pm 1.8$ & 0.22 \\
1-mg ODST (nmol/L) & $91.8 \pm 76.1$ & $26.26 \pm 8.95$ & 0.009 \\
\hline
\end{tabular}

BMI: body mass index; ODST: 1-mg overnight dexamethasone suppression test; LDL: low-density lipoprotein; HDL: high-density lipoprotein.

min) or hepatic failure, depression and alcoholism were excluded.

\section{Methods}

The selected patient underwent a 1-mg overnight dexamethasone (DXM) suppression test (ODST) as the first step screening test. They took $1 \mathrm{mg}$ of DXM at 23:00 and the sample blood test was collected on the next morning at 08:00 am for measurement of serum level.

The cut-off for cortisol suppression was $50 \mathrm{nmol} / \mathrm{L}(1.8$ $\mu \mathrm{g} / \mathrm{dL})$. The patients who had cortisol less than $50 \mathrm{nmol} / \mathrm{L}$ $(1.8 \mu \mathrm{g} / \mathrm{dL})$ were considered normal and did not need further exploration. If the cortisol level was above this cut-off, the patient was considered abnormal and underwent a 2-mg low-dose dexamethasone suppression test (LDDST) with the same cortisol cut-off. He took a $0.5 \mathrm{mg}$ of DXM at 06:00, 12:00, 18:00 and 24:00 for two consecutive days. At the third day, a blood sample test was used for cortisol measurement $[1,16]$. In the case of a positive diagnosis of CS with a lack of cortisol suppression in the LDDST, patients were hospitalized for etiological exploration and specific management. In addition, adrenocorticotropic hormone was measured. For the 8-mg DST, suppression was present when there was a decrease in cortisol concentration by more than $50 \%$ from baseline [17].

The clinical and biological characteristics of the patients were analyzed. Body mass index (BMI) values, defined by the weight ratio $(\mathrm{kg})$ on the square of the size (in meters), was interpreted in accordance with the classification adopted by the World Health Organization in 1998 [18]. Waist circumference has been interpreted according to the recommendations of the International Diabetes Federation (IDF): the android fat distribution was defined by a waist circumference greater than 94 $\mathrm{cm}$ for men and $80 \mathrm{~cm}$ for women [19]. Patients were considered hypertensive if they were: 1) already known hypertensive and treated; and 2) having a blood pressure $\geq 140 / 90 \mathrm{~mm} \mathrm{Hg}$ confirmed by at least two outpatient measures.

For hypertensive patients, blood pressure was considered well controlled when systolic blood pressure was $<140 \mathrm{~mm}$ $\mathrm{Hg}$ and diastolic blood pressure was $<80 \mathrm{~mm} \mathrm{Hg}$ (American Diabetes Association goals 2014) [20]. Low-density lipoprotein-cholesterol (LDL-C) was calculated according to the FRIEDWALD formula (for triglycerides (TG) $<4.4 \mathrm{mmol} / \mathrm{L}$ ): LDL-C $(\mathrm{g} / \mathrm{L})=\mathrm{TG}(\mathrm{mmol} / \mathrm{L}) / 2.2) \times 0.387$. High cholesterol was defined as total cholesterol $\geq 5.2 \mathrm{mmol} / \mathrm{L}$ or by taking a statin. Hypertriglyceridemia was defined as a TG level $\geq 1.7$ $\mathrm{mmol} / \mathrm{L}$ or by taking fibrates. Creatinine clearance was evaluated using the Cockcroft and Gault formula: creatinine clearance $(\mathrm{mL} / \mathrm{min})=(140-$ age $) \times$ weight $(\mathrm{kg}) /$ creatinine $(\mu \mathrm{mol} / \mathrm{L})$ $\times \mathrm{k}$; in women: $\mathrm{k}=1.04$; in human: $\mathrm{k}=1.25$. Hypokalemia was defined as serum potassium $<3.5 \mathrm{mmol} / \mathrm{L}$.

\section{Statistical analysis}

Statistical analyses were performed with SPSS software, version 13.0.

\section{Results}

A total of 221 patients were included in the study.

The mean age $\pm \mathrm{SD}$ of the patients was $58.7 \pm 8.78$ years. Overweight and obesity were found in $34 \%$ and $47 \%$, respectively. An android fat distribution was present in $76 \%$ of patients. The mean duration of diabetes was $10.84 \pm 6.55$ years. Hypertension was present in $35.7 \%$, with poor control in $34.2 \%$. In the study, our patients had hypercholesterolemia and hypertriglyceridemia in $63.8 \%$ and $47.1 \%$, respectively. The mean baseline $\mathrm{HbAl} \mathrm{c} \pm \mathrm{SD}$ was $10.9 \pm 1.8 \%$. In the study population, $95.9 \%$ were treated by insulin with or without oral therapy. On average, switching to insulin was $8.78 \pm 5.7$ years 


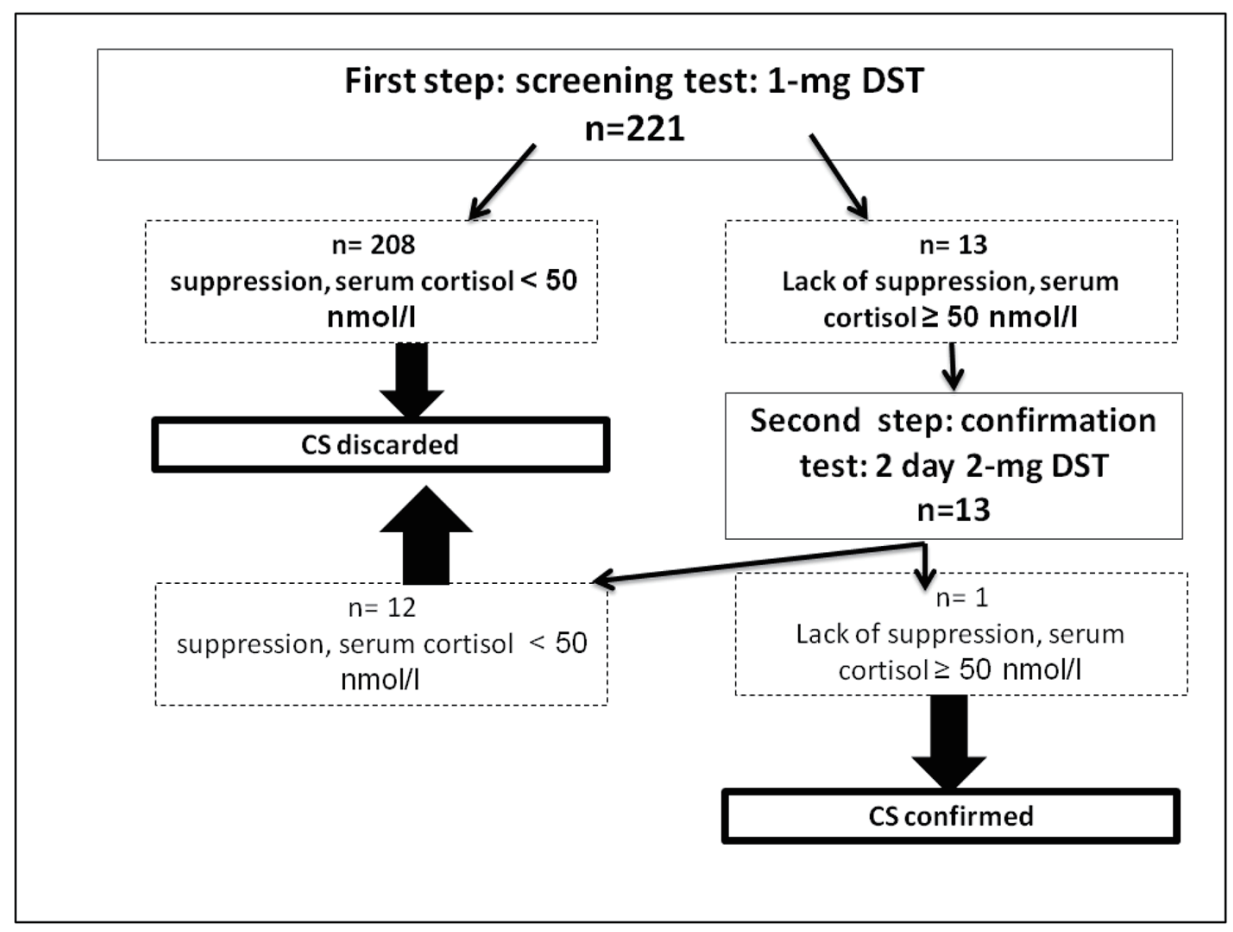

Figure 1. Results of the screening strategy for subclinical Cushing's syndrome in 221 type 2 diabetic patients with poor glycemic control. DST: dexamethasone suppression test.

after diabetes diagnosis. As non-specific signs of CS, facial erythrosis was noted in $23.1 \%$, Acanthosis nigricans in $16.3 \%$, and buffalo neck in $11.8 \%$ of cases. The association of excess weight with facial erythrosis or buffalo neck was noted in $19 \%$ and $11.3 \%$, respectively.

Thirteen (5.9\%) out of 221 patients failed to suppress cortisol on ODST and had a mean cortisol concentration after this test of $91.87 \pm 76.15 \mathrm{nmol} / \mathrm{L}$ (Table 1). There was a significant difference in BMI between DST suppressors and non-suppressors, but no significant difference in age, sex, or other metabolic parameters such as glucose, HbAlc, and

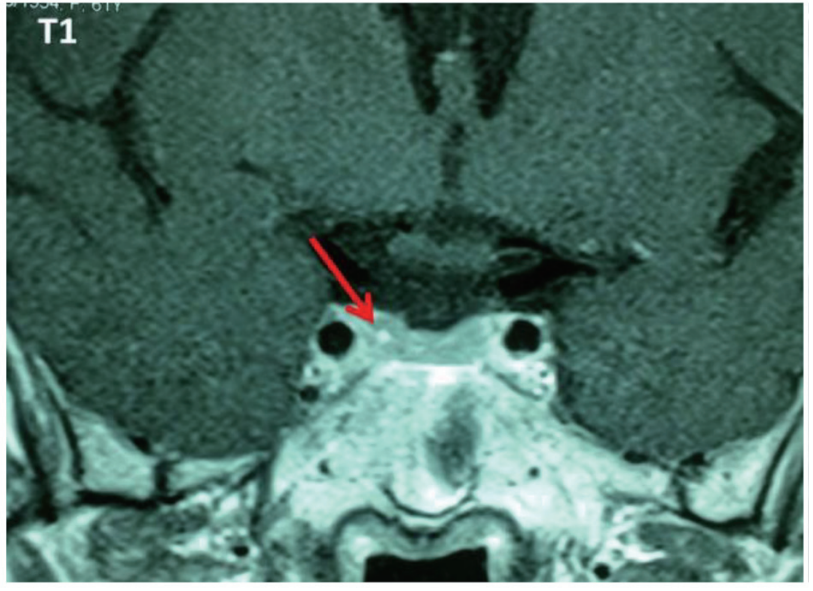

Figure 2. Pituitary lesion in hyposignal T1 with intense enhancement after injection of gadolinium. cholesterol. All non-suppressors were further evaluated by a 2 -mg LDDST. Out of these 13 , one patient $(0.45 \%)$ had a cortisol level $>50 \mathrm{nmol} / \mathrm{L}$ after LDDST $(71.87 \mathrm{nmol} / \mathrm{L})$, but he was a suppressor on 8-mg DST (Fig. 1). For this patient, the ACTH was at $17 \mathrm{ng} / \mathrm{L}$ and the patient had a pituitary lesion in magnetic resonance imaging (right anterior pituitary lesion $1.3 \mathrm{~mm}$ hyposignal $\mathrm{T} 1$, in hypersignal T2, taking strongly the contrast with the healthy pituitary, Figs. 2 and 3). As the clinical and biological presentation was not severe, we repeat a second MRI after 6 months. The second MRI showed an increase in the size of the pituitary lesion measuring $2 \mathrm{~mm}$. The patient was then referred for neurosurgery for microadenoma

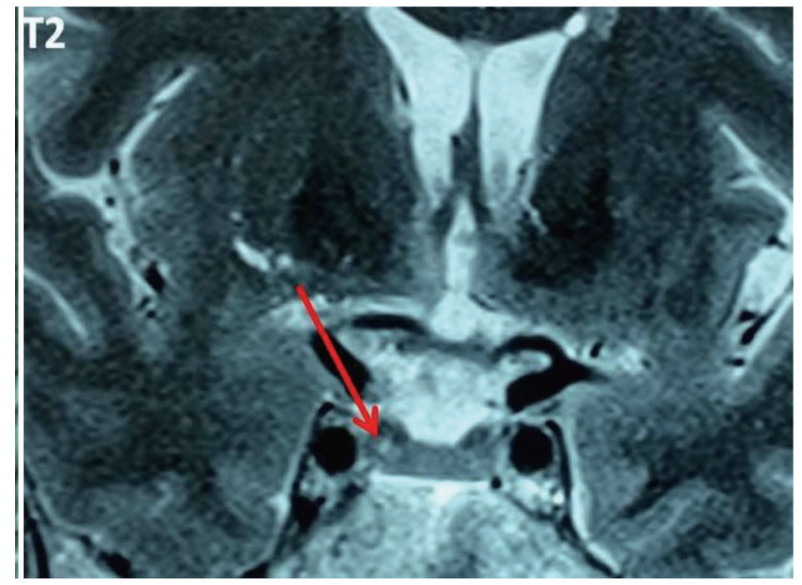

Figure 3. Pituitary lesion in hypersignal T2. 
Table 2. Previous Studies on SCS Screening in T2D Patients

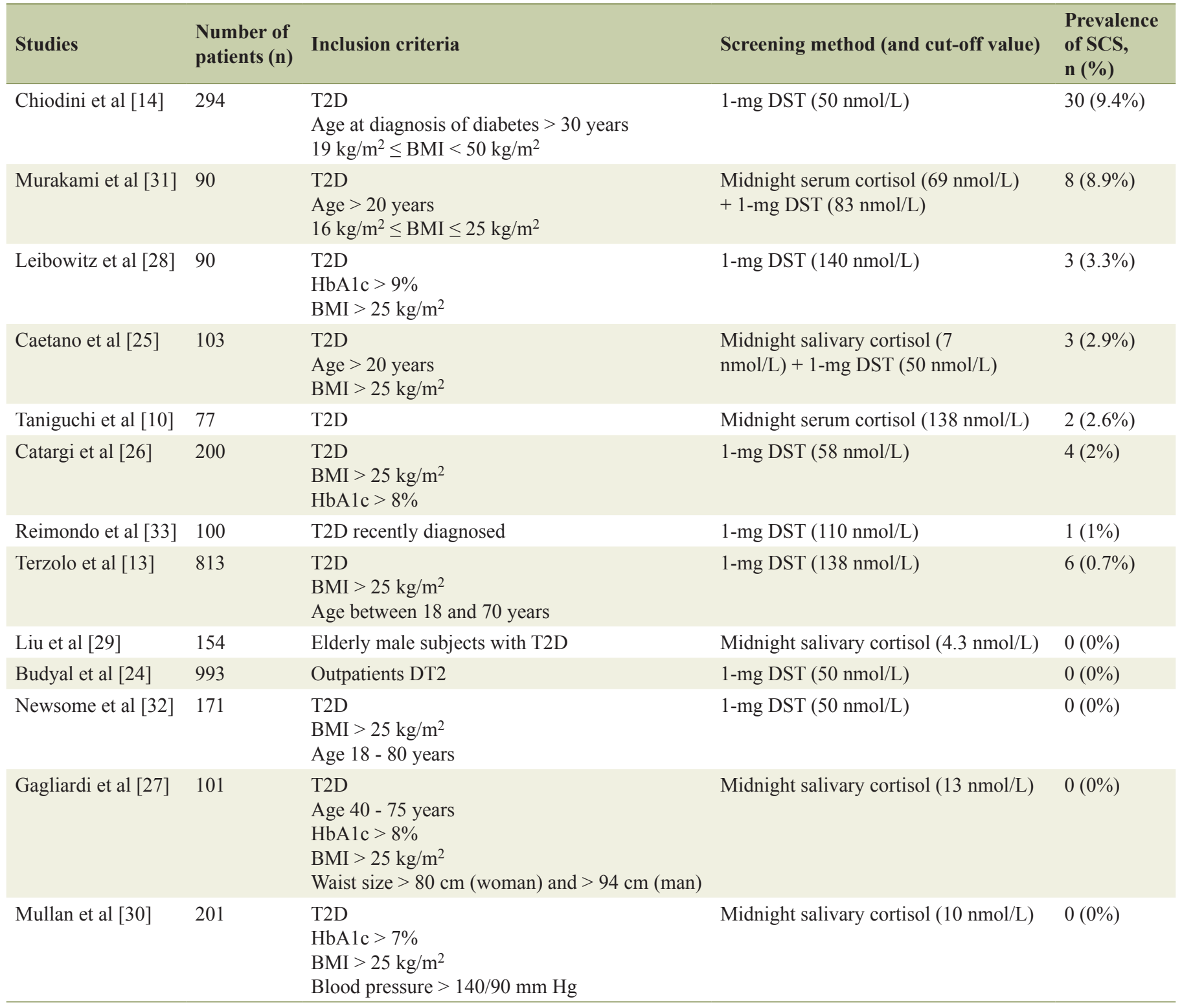

resection.

\section{Discussion}

Type 2 diabetes is a condition of chronic hyperglycemia, the main physiopathological mechanism of which is insulin resistance, followed by progressive insulinopenia [21, 22]. This insulin resistance during type 2 diabetes results in a clinical expression identical to that found during SCS, making it even less obvious the diagnosis of an SCS associated with diabetes $[12,23]$. Thus, we performed a systematic screening of SCS in T2D patients with chronic poor glycemic control. Of the 221 patients in our series, only one patient had an SCS (a prevalence of $0.45 \%$ of SCS in poor controlled T2D patients). Sev- eral other studies have been conducted since 1996 to determine the prevalence of SCS in populations of T2D subjects. The number of T2D patients included in these studies ranged from 77 to 993; the prevalence of SCS among reported T2D patients ranged from $0 \%$ to $9.4 \%[10,13,14,24-33]$. Differences in the results of all these studies can be explained mainly by the methodological differences: inclusion criteria, screening methods and their cut-off values, and even the hormonal diagnostic criteria of SCS since there is no definition of the SCS. Table 2 summarizes the main studies on SCS testing in T2D patients and their methodological differences.

In a previous Turkish study, an $8 \%$ false positive rate of a 1-mg ODST had been found in obese patients and it has been suggested that a 2-mg ODST could have more specificity compared to a 1-mg ODST [34]. In agreement with that 
study, the present study showed that cortisol suppression to ODST with the cut point of $1.8 \mu \mathrm{g} / \mathrm{dL}$ was false positive in 13 $(5.8 \%)$ patients and there is a significant correlation with BMI. Other potential confounders including stress, poor controlled diabetes, and the activators of cytochrome P-450 3A4 system such as statins should be considered. These results emphasized that high false positivity of ODST should be considered in the clinical practice and additional tools such as the 24-h urinary free cortisol or the late-night salivary cortisol test must be employed to confirm the diagnosis of CS.

Fixing the cortisol cut-off value at $50 \mathrm{nmol} / \mathrm{L}$ (which improves the sensitivity of the test), and eliminating situations that may induce pseudo-CS, the specificity of the 1-mg DST in our series was $94.5 \%$. In the other studies carried out in T2D patients, the reported specificities of the 1-mg DST range between $78 \%$ and $97.7 \%$. The comparison of our findings with those of the studies is difficult because, for the majority of these studies, the cut-off values for the DST as well as the SCS confirmation criteria were different from ours [14] (Table 2).

In our study, only one patient finally presented an SCS confirmed by the 2-day 2-mg DST. Given this result (a patient with SCS and 220 patients without SCS), we could not rely on this isolated case to perform an analytical study to identify predictive factors for SCS.

Screening for SCS in T2D patients has three foundations. A higher incidence of SCS in T2D patients compared with non-diabetic patients. Indeed, Chiodini et al [14] showed in his study that the prevalence of SCIC in T2D patients was significantly higher than in non-diabetics who were matched for age and $\mathrm{BMI}(9.4 \%$ vs. $2.1 \% ; \mathrm{P}=0.004)$. This frequency could reach $42 \%$ in T2D patients [15].

SCS is an independent and important cardiovascular risk factor to manage to reduce the morbidity and mortality of patients with T2D patients who are already at high cardiovascular risk. Several studies have shown an increased cardiovascular risk in patients with SCS. This risk is related both to the metabolic consequences and to a direct effect of excess cortisol on the vascular walls [9, 35-38].

The management of SCS would lead to an improvement in metabolic disorders. Indeed, Tachmanova et al [39] reported that the SCS treatment improves both glycemic control and hypertension and also allows weight loss. Taniguchi et al [10] clearly demonstrated an improvement in insulin sensitivity after treatment of SCS pituitary with a hyperinsulinemic euglycemic clamp, a reference technique for measuring insulin sensitivity [40-42]. Both patients had a marked improvement in glycemic control after treatment. In contrast, no randomized controlled trials demonstrating the impact of SCS on metabolic profile and cardiovascular mortality have been published to date $[7,15]$.

Based on a frequency argument, and knowing that the prevalence of SCS in the general population is estimated to be between $0.2 \%$ and $2 \%$, our results do not suggest a particular interest in systematic SCS screening in poorly controlled T2D patients, in any case no more than in the general population.

Thus, given the low incidence of SCS in poor controlled T2D patients, and the absence of studies demonstrating the benefit of SCS treatment on metabolic profile and cardiovascular morbidity and mortality, routine SCS screening in T2D patients does not seem relevant. Rather, we recommend: 1) a physical examination of diabetic patients in particular looking for signs of hypercatabolism; specific signs of the franc $\mathrm{CS}$, and particular attention to certain biological parameters (e.g. hypokalemia associated with hypertension) and certain co-morbidities (resistant hypertension, "idiopathic" osteoporosis). These situations represent grounds for CS research even outside of diabetes.

In the literature, many other authors do not recommend SCS testing in all T2D patients. Indeed, the majority of these authors recommend rather a targeted screening based essentially on the clinicobiological characteristics of the patients detected in their series.

For example, Terzolo et al [13] considered that the motivating factors for SCS screening were poorly controlled T2D patients, resistant hypertension, age of diagnosis of diabetes below 50 years, and lack of family history of type 2 diabetes.

Chiodini et al, who found the highest prevalence of SCS among T2D patients [14], showed that SCS was significantly associated with insulin-treated diabetes, poorly controlled and coexisting with hypertension or dyslipidemia. Six years after the publication of this study, they suggested that screening would be beneficial in patients with poorly controlled T2D patients despite appropriate treatment and adherence, especially those with associated osteoporosis or hypertension [7].

Finally, in a review article published in 2015 entitled "Screening for Cushing's syndrome: is it worthwhile [43]?" Shimon considers that the routine screening of SCS in T2D patients is not warranted. It should be considered only in young patients with resistant T2D patients or resistant HTA. The author did not specify the age limit and the definition of resistant diabetes.

\section{Conclusions}

SCS is rare among T2D patients. There is no benefit in routinely screening SCS for T2D patients with chronic poor glycemic control. This screening should be targeted and guided by the clinical and biological context.

\section{References}

1. Newell-Price J, Bertagna X, Grossman AB, Nieman LK. Cushing's syndrome. Lancet. 2006;367(9522):16051617.

2. Sulentic P, Grossman A: Cushing's Syndrome. In: De Groot LJ, Chrousos G, Dungan K, Feingold KR, Grossman A, Hershman JM, et al., eds. Endotext. South Dartmouth (MA), 2000.

3. Bolland MJ, Holdaway IM, Berkeley JE, Lim S, Dransfield WJ, Conaglen JV, Croxson MS, et al. Mortality and morbidity in Cushing's syndrome in New Zealand. Clin Endocrinol (Oxf). 2011;75(4):436-442.

4. Etxabe J, Vazquez JA. Morbidity and mortality in Cushing's disease: an epidemiological approach. Clin Endocrinol (Oxf). 1994;40(4):479-484.

5. Lindholm J, Juul S, Jorgensen JO, Astrup J, Bjerre P, 
Feldt-Rasmussen U, Hagen C, et al. Incidence and late prognosis of cushing's syndrome: a population-based study. J Clin Endocrinol Metab. 2001;86(1):117-123.

6. Mantero F, Terzolo M, Arnaldi G, Osella G, Masini AM, Ali A, Giovagnetti M, et al. A survey on adrenal incidentaloma in Italy. Study Group on Adrenal Tumors of the Italian Society of Endocrinology. J Clin Endocrinol Metab. 2000;85(2):637-644.

7. Chiodini I. Clinical review: Diagnosis and treatment of subclinical hypercortisolism. J Clin Endocrinol Metab. 2011;96(5):1223-1236.

8. Morelli V, Masserini B, Salcuni AS, Eller-Vainicher C, Savoca C, Viti R, Coletti F, et al. Subclinical hypercortisolism: correlation between biochemical diagnostic criteria and clinical aspects. Clin Endocrinol (Oxf). 2010;73(2):161-166.

9. Reincke M. Subclinical Cushing's syndrome. Endocrinol Metab Clin North Am. 2000;29(1):43-56.

10. Taniguchi T, Hamasaki A, Okamoto M. Subclinical hypercortisolism in hospitalized patients with type 2 diabetes mellitus. Endocr J. 2008;55(2):429-432.

11. Terzolo M, Bovio S, Reimondo G, Pia A, Osella G, Borretta G, Angeli A. Subclinical Cushing's syndrome in adrenal incidentalomas. Endocrinol Metab Clin North Am. 2005;34(2):423-439, x.

12. Terzolo M, Pia A, Reimondo G. Subclinical Cushing's syndrome: definition and management. Clin Endocrinol (Oxf). 2012;76(1):12-18.

13. Terzolo M, Reimondo G, Chiodini I, Castello R, Giordano R, Ciccarelli E, Limone P, et al. Screening of Cushing's syndrome in outpatients with type 2 diabetes: results of a prospective multicentric study in Italy. J Clin Endocrinol Metab. 2012;97(10):3467-3475.

14. Chiodini I, Torlontano M, Scillitani A, Arosio M, Bacci S, Di Lembo S, Epaminonda P, et al. Association of subclinical hypercortisolism with type 2 diabetes mellitus: a case-control study in hospitalized patients. Eur J Endocrinol. 2005;153(6):837-844.

15. Di Dalmazi G, Pasquali R, Beuschlein F, Reincke M. Subclinical hypercortisolism: a state, a syndrome, or a disease? Eur J Endocrinol. 2015;173(4):M61-71.

16. Arnaldi G, Angeli A, Atkinson AB, Bertagna X, Cavagnini F, Chrousos GP, Fava GA, et al. Diagnosis and complications of Cushing's syndrome: a consensus statement. J Clin Endocrinol Metab. 2003;88(12):5593-5602.

17. Castinetti F, Morange I, Conte-Devolx B, Brue T. Cushing's disease. Orphanet J Rare Dis. 2012;7:41.

18. Intersalt Cooperative Research Group. Intersalt: an international study of electrolyte excretion and blood pressure. Results for 24 hour urinary sodium and potassium excretion. BMJ. 1988;297(6644):319-328.

19. Alberti KG, Zimmet P, Shaw J, Group IDFETFC. The metabolic syndrome - a new worldwide definition. Lancet. 2005;366(9491):1059-1062.

20. American Diabetes A. Standards of medical care in diabetes - 2014. Diabetes Care. 2014;37(Suppl 1):S14-80.

21. American Diabetes A. Standards of medical care in diabetes-2015 abridged for primary care providers. Clin Diabetes. $2015 ; 33(2): 97-111$.
22. Giordano R, Guaraldi F, Berardelli R, Karamouzis I, D’Angelo V, Marinazzo E, Picu A, et al. Glucose metabolism in patients with subclinical Cushing's syndrome. Endocrine. 2012;41(3):415-423.

23. Krarup T, Krarup T, Hagen C. Do patients with type 2 diabetes mellitus have an increased prevalence of Cushing's syndrome? Diabetes Metab Res Rev. 2012;28(3):219227.

24. Budyal S, Jadhav SS, Kasaliwal R, Patt H, Khare S, Shivane V, Lila AR, et al. Is it worthwhile to screen patients with type 2 diabetes mellitus for subclinical Cushing's syndrome? Endocr Connect. 2015;4(4):242-248.

25. Caetano MS, Silva Rdo C, Kater CE. Increased diagnostic probability of subclinical Cushing's syndrome in a population sample of overweight adult patients with type 2 diabetes mellitus. Arq Bras Endocrinol Metabol. 2007;51(7):1118-1127.

26. Catargi B, Rigalleau V, Poussin A, Ronci-Chaix N, Bex V, Vergnot V, Gin H, et al. Occult Cushing's syndrome in type-2 diabetes. J Clin Endocrinol Metab. 2003;88(12):5808-5813.

27. Gagliardi L, Chapman IM, O’Loughlin P, Torpy DJ. Screening for subclinical Cushing's syndrome in type 2 diabetes mellitus: low false-positive rates with nocturnal salivary cortisol. Horm Metab Res. 2010;42(4):280-284.

28. Leibowitz G, Tsur A, Chayen SD, Salameh M, Raz I, Cerasi E, Gross DJ. Pre-clinical Cushing's syndrome: an unexpected frequent cause of poor glycaemic control in obese diabetic patients. Clin Endocrinol (Oxf). 1996;44(6):717-722.

29. Liu H, Bravata DM, Cabaccan J, Raff H, Ryzen E. Elevated late-night salivary cortisol levels in elderly male type 2 diabetic veterans. Clin Endocrinol (Oxf). 2005;63(6):642649.

30. Mullan K, Black N, Thiraviaraj A, Bell PM, Burgess C, Hunter SJ, McCance DR, et al. Is there value in routine screening for Cushing's syndrome in patients with diabetes? J Clin Endocrinol Metab. 2010;95(5):2262-2265.

31. Murakami H, Nigawara T, Sakihara S, Kageyama K, Yamashita M, Matsuki K, Tanabe J, et al. The frequency of type 2 diabetic patients who meet the endocrinological screening criteria of subclinical Cushing's disease. Endocr J. 2010;57(3):267-272.

32. Newsome S, Chen K, Hoang J, Wilson JD, Potter JM, Hickman PE. Cushing's syndrome in a clinic population with diabetes. Intern Med J. 2008;38(3):178-182.

33. Reimondo G, Pia A, Allasino B, Tassone F, Bovio S, Borretta G, Angeli A, et al. Screening of Cushing's syndrome in adult patients with newly diagnosed diabetes mellitus. Clin Endocrinol (Oxf). 2007;67(2):225-229.

34. Sahin M, Kebapcilar L, Taslipinar A, Azal O, Ozgurtas T, Corakci A, Akgul EO, et al. Comparison of $1 \mathrm{mg}$ and $2 \mathrm{mg}$ overnight dexamethasone suppression tests for the screening of Cushing's syndrome in obese patients. Intern Med. 2009;48(1):33-39.

35. Bernini GP, Moretti A, Oriandini C, Bardini M, Taurino C, Salvetti A. Long-term morphological and hormonal follow-up in a single unit on 115 patients with adrenal incidentalomas. Br J Cancer. 2005;92(6):1104-1109. 
36. Giordano R, Marinazzo E, Berardelli R, Picu A, Maccario M, Ghigo E, Arvat E. Long-term morphological, hormonal, and clinical follow-up in a single unit on 118 patients with adrenal incidentalomas. Eur J Endocrinol. 2010;162(4):779-785.

37. Siren J, Tervahartiala P, Sivula A, Haapiainen R. Natural course of adrenal incidentalomas: seven-year follow-up study. World J Surg. 2000;24(5):579-582.

38. Terzolo M, Pia A, Ali A, Osella G, Reimondo G, Bovio S, Daffara F, et al. Adrenal incidentaloma: a new cause of the metabolic syndrome? J Clin Endocrinol Metab. 2002;87(3):998-1003.

39. Tauchmanova L, Rossi R, Biondi B, Pulcrano M, Nuzzo V, Palmieri EA, Fazio S, et al. Patients with subclinical Cushing's syndrome due to adrenal adenoma have in- creased cardiovascular risk. J Clin Endocrinol Metab. 2002;87(11):4872-4878.

40. DeFronzo RA, Tobin JD, Andres R. Glucose clamp technique: a method for quantifying insulin secretion and resistance. Am J Physiol. 1979;237(3):E214-223.

41. Rabasa-Lhoret R, Laville M. [How to measure insulin sensitivity in clinical practice?]. Diabetes Metab. 2001;27(2 Pt 2):201-208.

42. Taniguchi T, Okamoto M, Ueno H, Tanaka J, Okamoto M, Hamasaki A, Yamada Y, et al. Use of the insulin sensitivity index obtained from oral glucose tolerance test in Japanese subjects. Diabetes Res Clin Pract. 2001;54(2):143144.

43. Shimon I. Screening for Cushing's syndrome: is it worthwhile? Pituitary. 2015;18(2):201-205. 